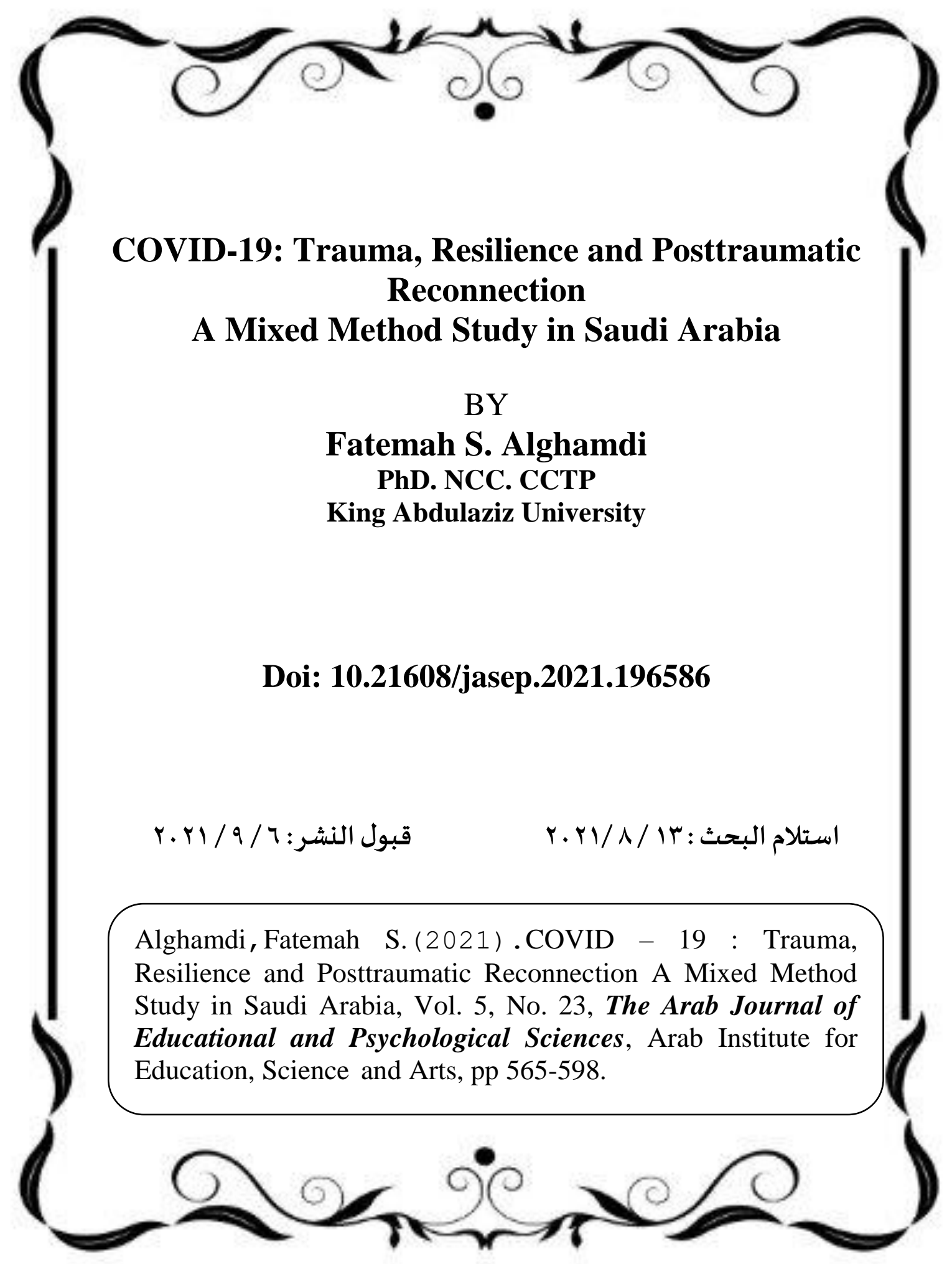




\section{COVID-19: Trauma, Resilience and Posttraumatic Reconnection A Mixed Method Study in Saudi Arabia}

\section{Abstract}

The coronavirus 2019 (COVID-19) pandemic has impacted people's mental health around the globe. Symptoms of trauma have increased drastically due to a perceived lack of control over the COVID-19 crisis, expectations of death or infection, and constant exposure to traumatic news. Resilience is defined as a person's use of coping skills to cope with traumatic events. The present research aimed to investigate the impact of resilience on COVID-19 trauma. An explanatory sequential design with mixed methods and two phases of research was employed.The first phase involved the use of the Arabic version of the Connor-Davidson Resilience Scale (CD-RISC) to measure resilience among adults. The total sample size was 778 participants. $T$ tests and correlation analysis were used to analyze the participants' questionnaire responses. The results showed a significant difference in resilience between male and female participants. Additionally, educational level and familial support were correlated with resilience.The second phase involved the administration of openended questions to gather in-depth information from 17 participants who answered the CD-RISC. Interpretative phenomenological analysis (IPA) was used in the coding process to analyze the qualitative data. The findings indicated that the COVID-19 crisis increased trauma symptoms and that participants exhibited cognitive, emotional, and behavioral resilience in coping with the pandemic. Moreover, a significant finding was that participants engaged in posttraumatic reconnection that emphasized reconnection with the self and others.

Keywords: Trauma, PTST, Resilience, OVID-19, Mixed-Method Research, Interpretative phenomenological analysis. 


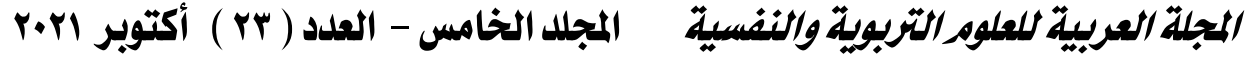

\section{Introduction}

The World Health Organization declared coronavirus 2019 (COVID-19) to be a pandemic that spread from China to the world. People have experienced stressors caused by the increasing numbers of positive cases and deaths of relatives, the profound impact of the pandemic on economies (Xiang, Yang, Li, Zhang, Zhang, Cheung, \& Ng. 2020), and social distancing measures (Rhodes, Lauderdale, Stocking, Howes, Roizen, \& Levinson, 2001). These stressors have impacted individual mental health, contributing to depression, anxiety, and trauma (Hirschberger, 2018). The continued exposure to COVID19-related trauma has been remarkable. Individuals have been exposed to trauma at several levels: a) the individual level, including the stress and fear of becoming infected; b) the community level, including the trauma and grief of losing friends and loved ones; and c) the global level, including trauma due following international news and social media that present real-life stories of those who have tested positive and medical personnel.

\section{Trauma}

The American Psychological Association (2019) defined trauma as a physiological and emotional reaction to a frightening incident, such as sexual abuse, physical abuse, domestic violence, war, natural and human-made disasters, suicides, homicides, and traumatic losses. Trauma was considered a psychological rather than a biological phenomenon until polyvagal theory was introduced (Porges, 2011). Other theories emphasized only the fight or flight response of trauma, but the polyvagal theory introduced a continuum of six responses to trauma: freeze, flight, fight, fright, flag, and faint. The first stage is to freeze, which is an orienting response to the interoceptive detection of danger. This stage is marked by hormone release and sympathetic nervous system (SNS) activation. Then, the fight or flight response takes over with a mild level of dissociation. The following stage is fright, when the individual responds with 
immobility because of the overwhelming threat. The flag stage is characterized by extreme arousal of the SNS, which must shut down, and the activation of the parasympathetic nervous system (PNS). If the danger continues, a final shutdown occurs in the faint stage (Schauer $\&$ Elbert, 2010). Therefore, trauma not only is a psychological issue but also includes a reaction of the body and nervous system.

\section{Trauma related to COVID-19}

Extensive exposure to traumatic news and the death of loved news makes the COVID-19 crisis a traumatic event. According to the Diagnostic and statistical manual of mental disorders DSM-5 (2013), trauma occurs when a person is directly exposed to or witnesses an incident that involves death or the threat of death, violence, serious injury, or sexual violence. Such crises impact an individual's mental and physical wellbeing, including through arousal and reactivity associated with the traumatic incident. Moreover, an individual who has faced traumatic events experiences dissociative reactions such as flashbacks that cause reoccurring intense stress and fearful memories.

Traumatic events impact an individual's cognitive and emotional status. A person with a history of trauma experiences cognitive difficulties, such as an inability to remember details about traumatic events, hypervigilance and a decreased ability to concentrate. A traumatized individual presents negative beliefs and expectations about life, the self, and the world (that the world is dangerous). Moreover, trauma experience has a negative impact on one's mood and increases fear, horror, anger, guilt, and shame. A traumatized person feels detached from others and disconnected emotionally and is unable experience pleasant emotions. Instead, aggression and self-destructive behavior are more likely to occur after a traumatic event. Thus, COVID-19 is considered a traumatic event because of the high level of stress, threats to life and safety , uncertainty, and lack of control over the infection. Table 1 illustrates the trauma criteria according to the DSM 5 and in relation to COVID19. 


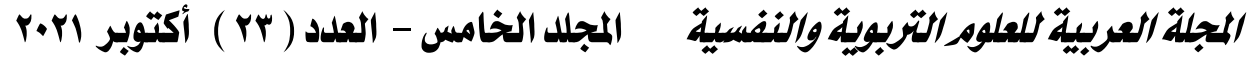

\section{Table 1 illustrates the trauma criteria according to the DSM 5 and in relation to COVID-19}

Criterion

Criterion A: stressor

Criterion B: intrusion symptoms
Direct exposure such as witnessing trauma, learning that a close person has been exposed to trauma.

Indirect exposure to details of trauma

Unwanted memories, nightmares, flashbacks, emotional distress, and physical reactivity
Criterion C: avoidance

Criterion D: negative alterations in cognition and mood

Criterion E: alteration in arousal and
Avoidance of traumarelated thoughts, feelings, or external reminders

Inability for recall, negative affect, decreased interest in activities, and

feeling of isolation

Irritability, aggression, risky behavior, hypervigilance, and
COVID-19

People from almost all countries around the globe have directly witnessed the COVID-19 pandemic. More than 9 million individuals have tested positive and nearly half a million have lost their lives in this pandemic (MHO, 2020). Additionally, noninfected people have been exposed to news and details from other patients on social media.

Physical and emotional distress have occurred because of unexpected nature and uncertainty surrounding coronavirus. Moreover, the absence of a cure and the shortage of medical support and hospital capacity have increased the level of trauma stressors. Several researchers have reported an increase in psychological issues related to the pandemic and trauma such as anxiety, fear, depression and frustration (Wei, Han, Liu, Liu, \& Huan, 2004; Wu et al., 2009).

Fear of infection and mistrust of the medical system has increased in many countries.

The WHO recommended social distancing, quarantine measures and isolation of individuals in homes, which has hindered people's daily activities, including going to work and school.

Because of changes in daily routines, sleeping and eating were impacted during the COVID-19 quarantine. 
reactivity

$$
\begin{aligned}
& \text { difficulty sleeping and } \\
& \text { concentrating }
\end{aligned}
$$

Criterion F: duration

Criterion G: functional significance
Symptoms lasting for more than one month

Symptoms that create distress or functional impairment
People have presented anxiety, been hypervigilant and engaged in obsessive shopping.

Individuals with traumatic experience are more likely to be angry, be less motivated to work, experience mood dysregulation, abuse alcohol/drugs, experience numbing, and feel isolated and social detached (Pacella, Hruska, \& Delahanty, 2013).

COVID-19 started in December 2019 and lasted more than 6 months. Millions around the world have lost their jobs and financially suffered because of the lockdown. People's daily routines changed. Students lost educational opportunities in countries that depended on traditional learning only.

Anxiety and stress are considered normal reactions to lifethreatening events, such as the COVID-19 pandemic. Stress-related symptoms, such as irritability, insomnia, limited performance, and relationship conflicts, have been observed especially among medical personnel (Vinkers, et al., 2020). Moreover, a fear of being infected, lack of information, uncertainty regarding the duration of quarantine, and stigma were found to contribute to the severity of psychological symptoms (Brooks, et al., 2020). Anger, fear of death, and depression were also reported during the COVID-19 crisis (Rana, et al. 2020). Mukhtar (2020) asserted that helplessness, hopelessness, ambivalence, and socioeconomic struggle were common issues among populations. Collective trauma is a traumatic event that impacts all individuals of a society. The collective trauma does not reflect the facts about a traumatic event occurring among a group of people but rather reflects their ongoing reconstruction of the trauma in an effort to create meaning from the traumatic event (Hirschberger, 2018). Collective 


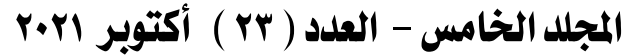

\section{المجلة العربية للعلور التربوية والنفسية}

trauma can be remembered beyond the time and space of traumatic events and the lives of direct survivors of traumatic events, such as the Holocaust (Mazur \& Vollhardt, 2015) and African migration (De Guissme \& Licata, 2017). Collective trauma alters the way that survivors perceive traumatic events and understand their relationship to the world and their group (Park, 2013). However, it has been proven that not all trauma survivors develop posttraumatic stress disorder (Miniati et al., 2009). Additionally, therapists do not intend for patients to forget the traumatic incident; rather, they aim to help patients manage the symptoms to resume productive lives. Therefore, utilizing positive coping skills and systematic support increases resilience, which is negatively correlated with trauma.

\section{Resilience}

Resilience is defined as the ability of the individual and society to respond to and heal from the impact of pandemics or disasters. It refers to the ability to return to normal life functioning in the face of adversity (Bonanno, Papa, \& O'Neill, 2001). A study on trauma and resilience reported that between $30 \%$ and $70 \%$ of individuals with traumatic experiences also reported positive change and development after a traumatic crisis (Joseph \& Butler, 2010). The COVID-19 pandemic has affected people's mental health differently than other traumatic events. Southwick \& Charney (2012) reported several factors that contribute to the individual level of resilience, such as poverty, healthcare accessibility limitation, poor living conditions, illiteracy, previous traumatic events, and lack of social support.

In a quantitative study, the researchers analyzed tweets during the COVID-19 lockdown to determine what emotions and coping skills were utilized during the pandemic. Several themes related to negative emotions such as anger, disgust, sadness, and fear emerged. Moreover, positive emotions, such as solidarity, trust and faith in becoming stronger after the crisis, and openness to the new lifestyle, were highlighted (Vibha, Prabhu, Kamath, \& Pai, 2020). Negative 
emotions are considered a normal reaction to a lack of control. The positive emotional experiences that were found to strengthen resilience included emotional expression and social support. These emotional experiences helped the individuals feel that they were not alone and promoted their wellbeing.

Another concept associated with resilience is posttraumatic growth. There are a limited number of studies that have examined this concept that have influenced its actual definition and construction. Posttraumatic growth was defined as the psychological process of finding the meaning of a disturbing event and regulating one's emotions associated with traumatic memories (Cormio, Muzzatti, Romito, et al., 2017). Tedeschi \& Calhoun (2004) asserted that posttraumatic growth is a positive adaptation that occurs as an outcome of coping with a traumatic experience. This process indicates a positive psychological change after one suffers from a traumatic event. However, the phenomenon of posttraumatic growth is not necessarily considered an outcome of a traumatic incident (Levers, 2020).

Moreover, resilience focuses on communication and problemsolving skills as psychological tools used by survivors (Bonanno, Papa, \& O'Neill, 2001), while posttraumatic growth emphasizes emotional maturity and interpersonal relationships. However, we cannot separate the cognitive, emotional, and behavioral impacts of trauma on people. Additionally, such skills are developed during the developmental stages when an individual faces crises or frustration. Therefore, the concept of posttraumatic growth does not perfectly describe resilience in the face of trauma.

\section{Aim of the study}

Based on previous literature, this study aimed to study the interaction between COVID-19 trauma and resilience. This research aimed to investigate the following questions: Is there a difference between male and female participants' CD-RISC scores? Does educational level correlate with resilience? Does social support 


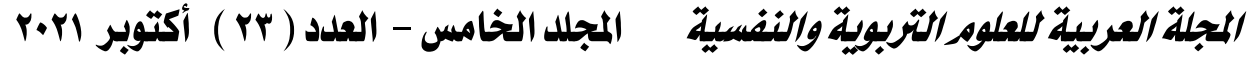

correlate with resilience? What is the lived experience of participants coping with the COVID-19 crisis?

\section{Method}

The present research is a mixed method study that utilizes a qualitative methodology to reach a better understanding of quantitative results. The present research applied an explanatory sequential design that involved two phases: first, the collection of quantitative data and analysis of the results and, second, the collection of qualitative data through open-ended questions and analysis of the findings.

In the present research, the data collection started with a quantitative questionnaire, and then statistically significant differences in the results were identified. Then, open-ended qualitative follow-up questions were sent to the participants to develop explanations and provide detailed insights into the results. Follow-up qualitative data are important for explaining and expanding quantitative results (Creswell \& Plano Clark, 2017). The sequential explanatory design was executed as follows: collection of quantitative data, analysis of quantitative data, production of quantitative results, identification of results for follow-up, collection of qualitative data, analysis of qualitative data, production of qualitative results, and interpretation of the quantitative and qualitative data. Appendix A illustrates the sequential explanatory design process.

\section{The first phase: Research design}

The present research utilized the Connor-Davidson Resilience Scale (CD-RISC) (CD-RISC: Connor \& Davidson, 2003), specifically, the Arabic version. The scale contains 25 items, all of which use Likert scale responses including not true at all, rarely true, sometimes, true, often true, and true nearly all of the time. The scale was sent electronically to the participants via email, text message, and social media. 
Sample: There were a total of N=791 participants. After incomplete responses were eliminated, the final total number of the participants was $\mathrm{n}=778$ individuals, including $\mathrm{n}=576(73.6 \%)$ females and $\mathrm{n}=202$ (26.4\%) males. All the participants reported that they understood the informed consent that was provided before to the scale and signed the consent form to indicate their agreement to participate. The age range of the participants was from 18-60 years old. A total of 667 (85.4\%) of the participants were from Saudi Arabia, and 111 (14.6\%) were not. The educational level of the participants ranged from high school or lower, $(\mathrm{n}=226,31 \%, \mathrm{M}=66.58, \mathrm{SD}=15.24)$ to a bachelor's degree, $(\mathrm{n}=443,56.3 \%, \mathrm{M}=68.65, \mathrm{SD}=14.47)$, to a graduate degree $(\mathrm{n}=109$, $13.8 \%, \mathrm{M}=74.97, \mathrm{SD}=13.46)$.

Data analysis: All statistical analyses were conducted using SPSS. Descriptive statistics were presented as frequencies and proportions for categorical variables and means and standard deviations for continuous variables. For all statistical tests, the significance was set at 0.05 or lower.

\section{The first phase: Results}

Gender: The results showed that the male participants $(M=71.30$, $\mathrm{SD}=15.15)$ demonstrated significantly better resilience scores than the female participants $(\mathrm{M}=68.10, \mathrm{SD}=14.57), \mathrm{t}(776)=2.66, \mathrm{p}=$ .008 . Cohen's $d=0.22$. The reliability test indicated a Cronbach's alpha $=.914$.

Educational level: A one-way analysis of variance (ANOVA) showed statistically significant differences between the group means according to education level, $\mathrm{F}(2,775)=12.41, \mathrm{p}=.000)$. Cohen's $\mathrm{d}=$ 0.69 , suggesting a moderate to high effect size. Post hoc analyses using the Tukey post hoc test for significance indicated that the mean resilience score of the participants with graduate degrees $(M=74.97$, $\mathrm{SD}=13.46)$ was significantly higher $(\mathrm{p}=.000)$ than that of the other two groups, namely, participants with high school degrees or lower $(\mathrm{M}=66.58, \mathrm{SD}=15.25)$ and participants with bachelor's degrees $(\mathrm{M}$ $=68.65, \mathrm{SD}=14.47, \mathrm{p}=.000)$. There was no statistically significant 


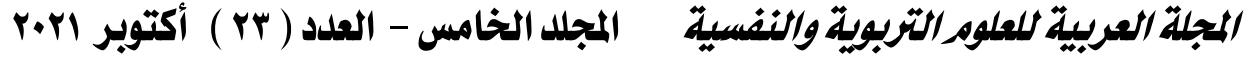

difference between participants with high school degrees or lower and participants with bachelor's degrees $(\mathrm{p}=.189)$.

Family support: The results showed that the participants who reported having family support $(\mathrm{M}=70.52, \mathrm{SD}=14.40)$ demonstrated significantly higher resilience scores than participants who reported not having family support $(\mathrm{M}=59.53, \mathrm{SD}=13.50), \mathrm{t}(776)=7.54, \mathrm{p}$ $=.000$ ). Cohen's $\mathrm{d}=0.79$ indicates a high effect size.

\section{Group Statistics}

\begin{tabular}{llllll} 
Total & Gender & $\mathrm{N}$ & Mean & $\begin{array}{l}\text { Std. } \\
\text { Deviation }\end{array}$ & $\begin{array}{l}\text { Std. Error } \\
\text { Mean }\end{array}$ \\
\cline { 3 - 7 } Resilience & Female & 576 & 68.10 & 14.568 & .607 \\
& Male & 202 & 71.30 & 15.150 & 1.066
\end{tabular}

\section{Independent Sample Test}

Total

Resilience

Equal

variances

assumed

Equal

variances

not

assumed

Levene's Test for t-test for Equality of Equality of Means

Variances

F $\quad$ Sig. $\quad \mathrm{t} \quad \mathrm{df}$

$\begin{array}{llll}.012 & .914 & -2.656 & 776\end{array}$

$-2.607 \quad 339.992$

\section{Independent Samples Test}

$\begin{array}{llllll} & & \text { t-test } & \text { for } & \text { Equality of } & \\ \text { Total } & \text { Means } & & & \\ \text { Resilience } & & \text { Sig. } & (2- & \text { Mean } & \text { Std. Error } \\ & & \text { taild) } & & \text { Difference } & \text { Difference } \\ & \text { Equal } & .008 & & -3.198 & 1.204 \\ & \text { variances } & & & & \end{array}$




\begin{tabular}{ll|lll} 
assumed & & & \\
Equal & .010 & -3.198 & 1.227 \\
variances & & & \\
not & & & \\
assumed & & &
\end{tabular}

\section{One way ANOVA}

Descriptive

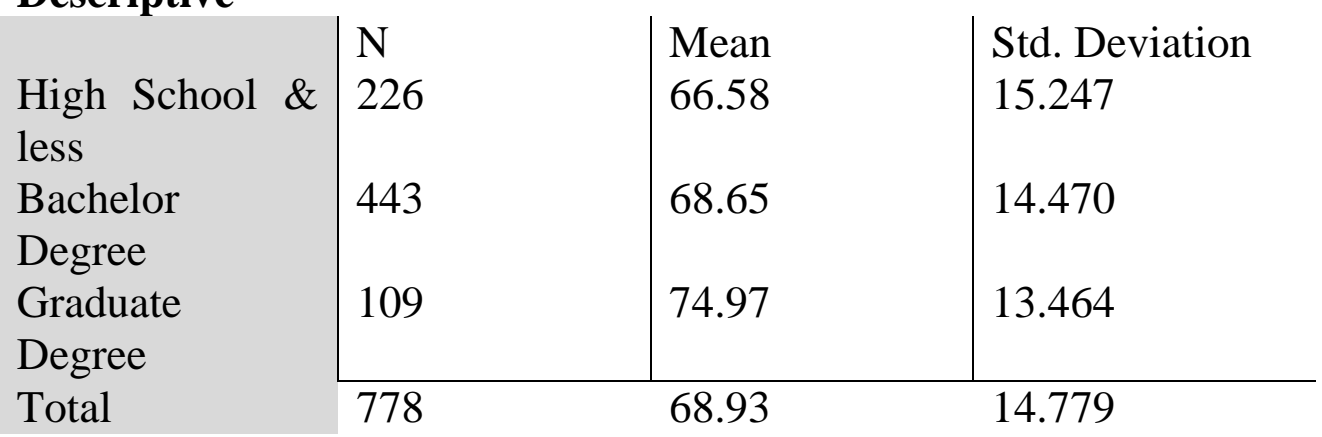

ANOVA

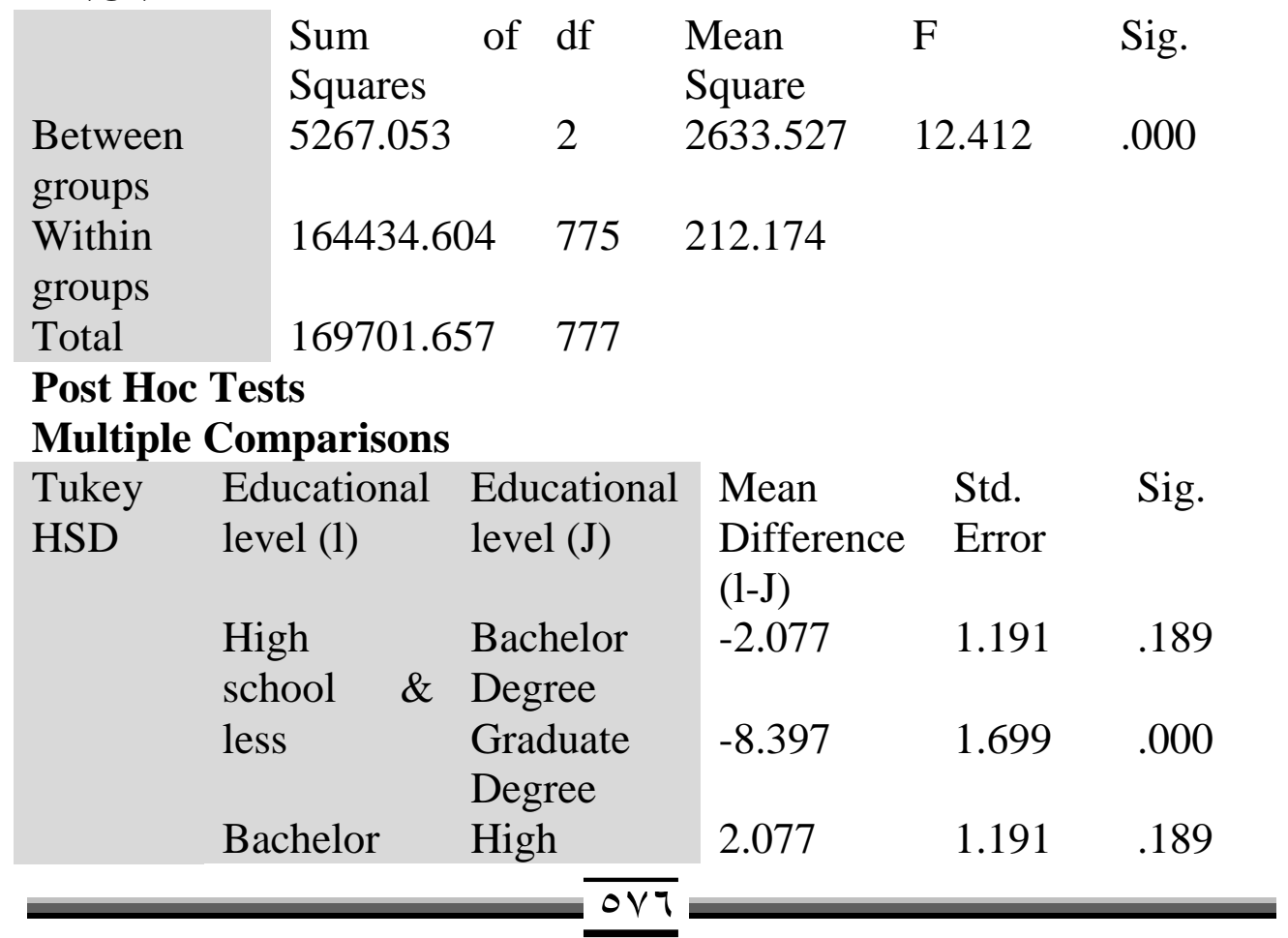




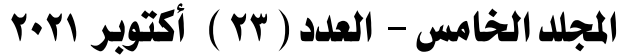

\section{المجلة العربية للعلوه الثربوبية والنفسية}

$\begin{array}{llllll}\text { Degree } & \begin{array}{l}\text { school \& } \\ \text { less } \\ \text { Graduate }\end{array} & -6.320 & 1.557 & .000 \\ & \begin{array}{l}\text { Degree } \\ \text { Graduate }\end{array} & \begin{array}{l}\text { High } \\ \text { School \& } \\ \text { Degree }\end{array} & 8.397 & 1.699 & .000 \\ & \begin{array}{l}\text { less } \\ \text { Bachelor } \\ \text { Degree }\end{array} & 6.320 & 1.557 & .000 \\ & & & & \end{array}$

\section{Effect size}

\section{Effect size f Overall effect size f Group 1 vs. group 2 0.6853 Group 1 vs. group 3 0.2393 Group 2 vs. group 3

\section{The second phase: Research design}

This research utilized interpretative phenomenological analysis (IPA) (Smith \& Osborn, 2007) to analyze the data that were collected from the open-ended questions. The = IPA process was as follows: a) searching for themes in the first case, which required reading and taking notes on the meanings of the themes; b) connecting the themes by creating tables and clusters; c) continuing the analysis with the other cases; and d) writing the themes and reconstructing the statements into a narrative.

Participants: There were a total of $\mathrm{N}=22$ participants; five participants were excluded due to incomplete responses, so the final total number of participants was $n=17$, including $n=9$ females and $n=8$ males. The age range of the participants was 18-60 years old, with $\mathrm{n}=11$ aged $18-30$ years old, $n=2$ aged $30-40$ years old, and $n=4$ aged 45-60 years old. The participants were considered educated: 2 participants had master's degrees, 12 had bachelor's degrees, and 3 had high school diplomas. 
Data collection: Three open-ended questions were used to gather in-depth information related to the participants' experience of the COVID-19 crisis. The questions were presented in Arabic and sent electronically to the participants who had informed the researcher that they answered the CD-RISC. The open-ended questions were as follows: How did COVID-19 positively impact your personality and lifestyle? What are the lessons learned from the COVID-19 quarantine? How has the pandemic changed your point of view about life?

Coding: The participants' answers were translated to English by two translators to ensure validity, and they were transcribed. Coding is used in qualitative research to generate names and labels for the studied phenomena (Marshall \& Rossman, 2016). The first phase of the coding was open coding, which was conducted in Atlas TI through line-by-line coding. This process generated 33 open codes, and each open code was linked to another existing open code (Appendix B). The second phase was selective coding. The researcher utilized SimpleMind software (Appendix C) to illustrate the relationship between the open codes. Two peers were consulted regarding the clustering of the open codes to ensure validity. The final phase was the theoretical coding, which focused on the most related of the identified codes. Three major themes emerged in the present research: trauma symptoms related to COVID-19, resilience, and posttraumatic reconnection.

\section{The second phase: Findings}

Several important findings emerged from this investigation. In total, 33 themes were derived from the informants' experiences during open coding. During the theoretical coding, these themes were organized into three clusters. The first cluster was COVID-19 trauma, the second was resilience, and the third was posttraumatic reconnection.

\section{COVID-19 Trauma}

The first cluster that emerged in the present research concerned traumatic experience related to COVID-19. This crisis is considered 


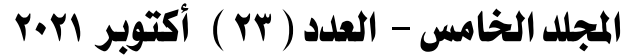

\section{المجلة العربية للعلوم التربوية والنفسية}

traumatic because it has caused extensive fear of dying in a lifethreatening situation. Moreover, individuals' exposure to traumatic news, reports of death and videos of dying individuals and medical personnel has traumatized them and impacted their mental and physical health. In this study, trauma symptoms manifested more often among female $(n=5)$ than male $(n=1)$ participants. The themes that emerged referred to symptoms of trauma: depression and loneliness, fear, anxiety, and dissociation.

\section{Depression and loneliness}

Depression is a mood disorder that involves an individual feeling sadness, hopelessness, anger, irritability, and frustration and losing interest in leisure time. Depression impacts the quality of sleep and reduces appetite. Additionally, it impacts an individual's cognition, emotion, and physical wellbeing. In the present research, depression was found to be a symptom of trauma related to the COVID-19 crisis. Moreover, the results suggest that depression can be viewed as a reaction to routine change and social isolation. Social distancing and major lockdowns in jobs and schools impacted several participants' mental health and increased depression. The participants indicated experiencing depression and changes in their daily routines, decreased mobility, and expectations of the death of a loved one; for example, Participant 10 stated, "...life became slow and calm during the quarantine....". Senses of hopeless and helplessness were indicators of sociality, such as for Participant 16, who thought about death and trauma: "...my point of view of life and what is happening has changed... I could die anytime... life could end in a second...".

Depression impacted the participants' physical wellbeing. Participant 14 reported changes in sleep and insomnia because of negative thoughts and feelings related to COVID-19 trauma: "I stay awake all night until the early morning thinking about what could happen next and watching the news". Participant 9 highlighted the negative impact of the quarantine on physical health: "...many people 
became physically less active, which impacted their mental health... they have to stay home and not interact with others". Participant 15 referred to somatic symptoms, which indicated depression "...I feel tightness in my throat... life has become like living in a jail...". Several participants indicated feeling isolated and lonely, such as Participant 11 and Participant 6. The symptoms of loneliness derived from a lack of social support and familial communication during the pandemic; for example, Participant 6, noted "You should take care of yourself... you should depend on yourself to fulfill your needs".

\section{Fear}

A fear of COVID-19 infection and death was expressed in the participants' answers. All 17 participants highlighted that people should be aware and conscious and take care of their physical wellbeing to avoid contracting the disease. Participant 15 indicated that people continued to practice social distancing because of the fear of infection: "People are conscious of getting near you and being in big gatherings... they are more aware of how to protect themselves from the disease". Participant 2 was traumatized because the disease and the increasing number of deaths that happened suddenly: "...this [COVID-19 infection] happened all of the sudden... I preferred to stay home to protect myself except for a couple of hours to go out for shopping". Additionally, a fear of losing a significant person was communicated by several participants, such as Participant 17, who linked his/her identity and purpose in life to living with family and connecting with friends: "The whole value of living is to be able to see your family, friends, and loved ones".

\section{Anxiety}

Anxiety refers to negative and pessimistic thoughts related to an unknown future. The theme of anxiety surfaced among several participants. Staying home and reducing daily activities to a minimum seemed to increase their anxiety and prompt them to find meaning in life and plan their futures. Participant 12 used the quarantine time to focus on his goals because he felt that they he had not previously 


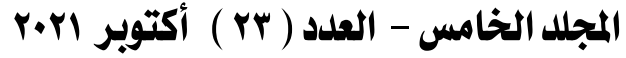

\section{المجلة العربية للعلوم التربوية والنفسية}

processed or planned them and prepared for his future: "This time [the COVID-19 pandemic] let me think about my goals and plan for my future... what I need to achieve my goals...". Moreover, anxiety seemed to mostly be existential anxiety, which provoked many questions; for example, Participant 16 stated, "...my point of view of life has changed... I could die anytime... life could end in a second...". Therefore, anxiety is a symptom of trauma, as individuals cannot predict the future and experience a lack of control.

\section{Dissociation and depersonalization}

Dissociation is a traumatic reaction in which a traumatized person feels that the traumatic event has happened to someone else and the experience appears to be unreal. Dissociation is a defense mechanism to reduce stress, fear, and anxiety due to traumatic incidents. Participant 2 could not believe that COVID-19 has impacted millions of people: "I had never thought or imagined that I would stay home for several months... it is like a dream... this could not be real ...this happened all of the sudden and I was not prepared... I preferred to stay home to protect myself from the infection".

Participant 13 viewed the COVID-19 crisis as similar to a movie that provoked anxiety uncertainty and unbelievable challenges: "When I watch science fiction movies, I used to wonder how people would live in such a condition... I have never thought that I would need to wash my hands after touching anything like the elevator or cash or shopping carts... I know it is unbelievable, but we have to do it”. Participant 15 experienced paranoia and depersonalization: “... I do not believe the numbers of victims and the expected cost of damages... because social media and the news exaggerate the number... this is impossible to be real". Therefore, dissociation and depersonalization have been caused by the traumatic COVID-19 crisis. 


\section{Resilience}

The second cluster that emerged in this research concerned resilience, which is defined as the ability to cope with a traumatic incident and heal from psychological wounds after trauma. Although participants in the present research revealed symptoms of trauma related to COVID-19, they also showed resilience. Among the informants, more male participants $(n=8)$ than female participants $(\mathrm{n}=9)$ showed resilience skills. Three major themes emerged: cognitive resilience, emotional resilience, and behavioral resilience.

Cognitive resilience is the ability to think, reflect, and make meaning about an experience and develop a point of view of life. Participants reported some symptoms of depression because of the quarantine; however, they also spent time thinking and reflecting on their goals, lives, and relationships. Several participants thought about their futures, which acted as a resilience skill to improve the present moment. Participant 11 acknowledged the positive impact of social distancing: "Quarantine and social distancing cleared my mind... I thought and reflected upon previous decisions that I have made to improve my future". Participant 12 shared, "This time (the COVID-19 pandemic) let me think about my goals and plan for my future... what I need to achieve my goals".

Moreover, Participant 6 reflected on their thoughts and reconnection with the self that were previously prevented by the distractions of daily busy life: "I thought about my lifestyle and I reconnected with myself and others... I enjoyed being calm". Participant 13 used to be distracted before the quarantine: "I notice huge differences in all aspect of my life... spiritual, financial, familial reconnection... I was able to think and reflect on my goals, and I was able to sit... to be centered and grounded... calm, and my mind became very clear". A similar experience was mentioned by Participant 17 : "Staying home reduced the distractions... I became centered and aware of my surroundings... my cognitive abilities such as focusing have 


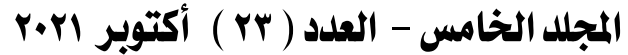

\section{المجلة العربية للعلوم التربوية والنفسية}

strengthened". Thus, participants used the quarantine time to think and reflect on their lives, goals, and future.

Emotional resilience is described in this study as the participants' abilities to control their emotions related to COVID-19 trauma and to experience healthy and productive feelings. Several healthy emotions, such as acceptance, adaptation, awareness, and gratitude, were expressed in the participants' discussions. Notably, acceptance does not mean that the participants liked the situation; instead, they tried to move on rather than to freeze. Acceptance helped the participants control what they could and let go of what they could not.

Participant 7 indicated that the stressful time during the COVID-19 crisis promoted self-acceptance: "I used to limit my abilities and skills... now I found alternative ways to enjoy my life... I have become more aware of myself... I accept myself...". Participant 17 practiced self-acceptance and reflected on social acceptance: "I used to judge people who love to stay at home... now I accept others' lifestyle and understand their point of view... for instance, going to the supermarket is a struggle for a lot of people... I understand them better now... three months of social distancing and staying home make you think about yourself, others, and life...". Appreciation of the ability to accept and adapt was communicated by Participant 7: "I became more aware of human abilities and their unique ways to move on during crisis". Participant 4 noted, "Human beings are able to adapt under any condition. I accept the changes that I have gone through [during COVID-19], and I am grateful of everything that I have". Participant 2 emphasized, "Life is not going to stop; we are able to adapt and continue living no matter how bad the situation is".

Participant 7 indicated appreciation and gratitude for the variety of ways that people have adapted to COVID-19: "People are so strong; I am impressed by humans' abilities to adapt and let go of things that they thought they could not live without. I believe this time 
[the COVID-19 pandemic] is a difficult and stressful time, but it is eye opening". Participant 8 described feeling appreciative: "We used to have a lot of things that we have never cared about... never appreciated them... this pandemic has been eye opening regarding the good things that you have in your life, to be grateful and thankful". Additionally, gratitude was evident in the response of Participant 15: "People used to waste their time, effort, and money on thing that are useless... we appreciate what we have and value things that in our hands... not to focus on things that I do not have".

Participant 13 appreciated the governmental support and plan for controlling the pandemic: "Safety and health are the main priority for people... following directions and trusting the orders and staying home... I am thankful that the government (in Saudi Arabia) ordered the social distancing and lockdown of schools and work... they take care of us... I feel... I strongly belong to a great nation [Saudi Arabia]". Thus, the experience of healthy and strong emotions was utilized as a coping skill and resilience skill to minimize the negative impact of COVID-19 trauma.

Behavioral resilience: Resilience was manifested in the participants' behavior and strategies to cope with COVID-19 trauma. Behavioral resilience includes a) utilizing personal skills that one already had before the trauma and b) learning new skills. Several participants used personal skills to overcome trauma and the difficulties of quarantine and increase their reconnection with the self. Reading was a coping skill that helped Participant 10 reduce trauma symptoms: "I became aware of myself, reconnected and calmed. I used this time to professionally develop my skills and read books". In addition to reading, Participant 2 used other coping skills: "I became a better reader; I focused on myself, and I tried to learn new skills such as drawing and cooking new recipes". Participant 8 returned to hobbies, that reminded him/her of good times: "I discovered some hobbies that I never thought I could have; I also tried sewing a dress for my granddaughter". 


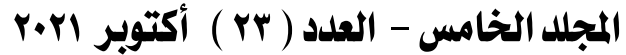

\section{المجلة العربية للعلور التربوية والنفسية}

Participants used resilience to develop new skills and improve professional skills. Participant 10 indicated that quarantine was an opportunity to focus on professional skills: "Life became slow and calm during the quarantine... I had the chance to develop my skills by attending workshops, conferences, and lectures that enhanced professional development". Similar to Participant 10, Participant 4 viewed the crisis as an opportunity for professional growth: "My productivity and achievement levels have increased because transportation took several hours of my day". Moreover, Participant 9 reported, "This time [the COVID-19 crisis] calmed me down... my day became slower, and work stress and traffic were reduced. I developed technical skills like using computer and smart phone applications".

Participant 11 utilized the time for self-exploration and learned a new skill that could offer a new professional start: "I went back to hobbies that I have loved since I was a kid, such as reading... and I discovered new skills that I am good like marketing and real estate management". Engaging in healthy activities and developing new skills helped the participants overcome trauma symptoms and increase their sense of control. Therefore, maintaining cognitive resilience skills, expressing healthy emotions, and continuing healthy behaviors helped the participants strengthen their reconnection with the self and their communities.

\section{Posttraumatic reconnection}

The third major cluster that emerged in the present study was posttraumatic reconnection. In the present research, posttraumatic reconnection is considered an outcome of the interaction between trauma symptoms and resilience. There were two themes related to the posttraumatic reconnection: a) reconnection with the self and b) community reconnection. Reconnection with the self refers to the individual's ability to utilize resilience and coping skills to heal from a traumatic incident, such as the COVID-19 crisis. Reconnection with 
the self also involves finding meaning in the incident. Reconnection with the self includes leading a healthy lifestyle and having healthy connection with family (microsystem).

Participant 7 focused on adopting a healthy lifestyle that promoted healthy thoughts and emotions: "I go to bed at the same time and wake up at the same time every day... I completely stopped eating fast food, and I replaced it with healthy and balanced meals... exercising for two hours every day was the best way to reduce the boredom and refresh my energy". Participant 9 indicated that reconnection with the self starts with awareness, which leads to healthy behavior: "Awareness increases positive behavior to be able to protect yourself, such as washing your hands and not touching your face".

Participant 11 emphasized financial awareness during the COVID-19 crisis: "People became aware of their budgets and learned how to spend money wisely... they learned how to save money and manage their household items... not to get things that they do not need. They also adopted a healthier lifestyle by washing their hands a lot". Moreover, Participant 17 viewed reconnection with the self from a holistic perspective: "People should take care of their wellness... physical, mental, and professional... this time is a good time to focus on yourself, goals, relationships, and your work". Participant 13 reflected on reconnection with the self as an aspect of maturity: "I feel I became more mature... my interests grew... I became aware of my physical health... I ate healthy and practiced every day, and I reached my goal of losing weight".

\section{Social reconnection}

Family reconnection was mentioned by several informants. Participant 15 indicated that reconnection with the self involved forming healthy relationships with significant people: "This [COVID19 quarantine] impacted me positively... it improved relationship with my family... we communicate better... we eat healthy food together... I used to eat junk food out [at restaurants]... my family and I share a lot 


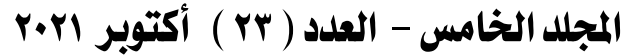

\section{المجلة العربية للعلوم التزبوية والنفسية}

of fun time, and we compete to show our creativity at home". Additionally, Participant 16 found alternatives to enjoy the time in quarantine and strengthen communication with family: "I maintained healthy connections with friends and family... I became a healthier person... sleeping at night... because we are not able to go out and meet others... I also eat with my family instead of going out to eat".

Moreover, Participant 7 used the quarantine time to foster family relationships to increase support: "... my family and I used to avoid dealing with our issues and made excuses all the time. Now we communicate better... our relationship has become stronger". Participant 8 maintained connections to family members despite social distancing: "The relationship with my adult children and family became stronger... we are closer to each other because we all used an application to be connected to each other". Additionally, Participant 2 utilized many strategies to connect with significant people and created meaning from the trauma and familial reconnections: "I have learned that communication and connecting with others are not limited to physical closeness. Although the COVID-19 regulations focused on social distancing, we are connected by using online applications". Therefore, resilience helped the participants engage in reconnection with the self through the formation of healthier relationships with the self and significant people. Community reconnection was also reported among the participants.

\section{Community reconnection}

Community reconnection refers to a healthy relationship with the macrosystem, including the community and the nation. Feeling connected to a greater entity increases the sense of responsibility and trust in decision makers. Additionally, feeling connection with other people who have experienced similar traumatic incidents is meaningful. Participant 15 indicated that people became aware and responsible for helping the community stay safe: "People are conscious of getting out and being in big gatherings... they are more 
aware of how to protect themselves from the disease". In addition, Participant 14 discussed social changes such as adopting healthy habits that have impacted the community: "People used to neglect healthy habits... they were ignorant about it... now they are more aware of how to protect themselves and loved ones against the infection".

Furthermore, Participant 13 highlighted following the advice from the government to stay healthy: "safety and health are the main priority for people... following directions and trusting the orders and staying home... I am thankful that the government [in Saudi Arabia] ordered the social distancing and lockdown of schools and work... they take care of us... I am very proud of belonging to a great country". The participants highlighted a deeper level of community reconnection, which improved the critical and traumatizing situation: "...Life is all about the way you perceive it, and you have the ability to improve it. All of us should be responsible for helping our nation control this decease".

Thus, connecting to a community, nation, or a larger group promoted a sense of safety and belonging that supported resilience and posttraumatic connection. The diagram in the appendix illustrates the themes and clusters.

\section{Discussion}

This research utilized a mixed method design to study trauma and resilience related to the COVID-19 pandemic. The present research used the electronic version of the CD-RISC to measure resilience among 778 participants. In addition, this research used three openended questions to collect detailed information on the participants' experiences of trauma and resilience during the crisis.

\section{Trauma}

The results indicated significant differences in resilience between males and females. Lower resilience scores indicated that the participants had fewer coping skills and were more likely to be traumatized by the COVID-19 incident. Additionally, gender 


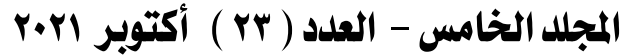

\section{المجلة العربية للعلومر الثربوية والنفسية}

differences in trauma were manifested in the themes identified from the open-ended questions, with more female participants $(n=5)$ than male participants $(n=1)$ experiencing trauma symptoms. Women are considered to be a vulnerable and underserved population and are more likely to be traumatized than men (Lopez Castro, Saraiya, \& Hien, 2017). There are several risk factors that increase the likelihood of trauma among women, such as lower education levels, poverty, and unemployment (Schafer, et al. 2019). Moreover, women face domestic violence, human trafficking, abuse, sexual assault, lack of social support, and mental health issues, which are considered risk factors for trauma (The National Center for PTSD, 2019).

Moreover, participants presented several responses to trauma, such as freeze, fight, flight, fright, flag, and faint, which were emphasized in the responses. This finding is supported by the polyvagal theory by Schuer \& Elbert (2010), who reported the 6 Fs of trauma. The participants' freeze phases were manifested as shock and an inability to think about the COVID-19 crisis. Fight and flight were utilized by participants to protect their physical and mental health, and resilience skills were utilized to face stressors. Additionally, fright was a normal reaction during COVID-19. Finally, participants indicated experiencing dissociation and depersonalization during this crisis as means of helping reduce stress.

\section{Resilience}

Educational level is a significant protective factor against trauma. There is a significant relationship between educational level and resilience. Several previous studies have found that resilience is an indicator of a high level of educational performance (Robbins, Kaye \& Catling, 2018). However, no previous studies have proposed educational level as a component of resilience.

Education increases awareness and cognitive skills, such as analyzing, thinking, and planning skills, which assist individuals in reducing the stress of trauma, give them a sense of control, and help 
them create healthy coping skills during the crisis. This finding aligns with research that found that resilience creates hope, improves quality of life, and increases positive self-perception (Bustos, 2012; Soto, 2016). Cognitive resilience was observed among the participants who engaged in thinking and reflection on their lives, created meaning from the experience, and planned for the future. Highly educated individuals were able to use the quarantine period to develop their professional skills and to learn new hobbies. This strategy helped the participants to be resilient and reconnect with themselves and others.

Moreover, the statistical analysis in the present research showed a significant relationship between resilience and family support. This result is consistent by several studies (Herdiana, Handoyo, \& Suryanto, 2018; Turliuc, Danila, \& Mairean, 2013; Gold, 2001; \& Hooper, 2008). Individuals rely on family and significant individuals to process and cope with the traumatic experience. Additionally, connecting to the family increases self-awareness and acceptance among the participants. This finding was supported by research that indicated that the core mission of resilience was to illuminate and improve the process of healing from a traumatic incident (Luthar \& Brown, 2007).

Resilience is considered a personality trait that an individual develops during the developmental stages and learns how to utilize in traumatic situations. The individual activates this personality trait according to the situation. Thus, resilience is a personality trait that has already been learned and developed, and individuals use it to reduce stress during a crisis.

\section{Posttraumatic reconnection}

The present research showed that the participants engaged in posttraumatic reconnection. Posttraumatic reconnection differs from posttraumatic growth. Posttraumatic reconnection focuses on finding the meaning of an experience and reconnecting with the self and one's social networks. This finding is consistent with Celinski \& Allen's research (2016) that explained resilience as a spectrum of recovery, 


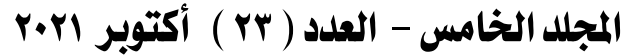

\section{المجلة العربية للعلوم التربوية والنفسية}

sustainability, and growth. However, resilience is the coping skills, strategies, and mechanism that are used during a traumatic incident, and posttraumatic reconnection is the individual progress of readjusting and connecting to self and others.

Moreover, a sense of belonging and a feeling of being in control help individuals with traumatic experience refrain from rumination and self-recrimination, which leads to increased posttraumatic reconnection. This finding, in line with research on previous crises, illustrates how survivors engage in posttraumatic reconnection, similar to how the survivors of $9 / 11$ found meaning in the attacks by reflecting on their responsibilities and personal values, such as spirituality and compassion, and forming strong friendships and other social bonds (Eakman, Schelly, \& Henry, 2016). Additionally, these findings are consistent with a previous study that confirmed social support, self-efficacy, and sense of coherence as factors related to healing from trauma (Roditi, Bodas, Jaffe, Knobler, \& Adini 2019; Di Giuseppe et al., 2020).

Reconnection was mentioned by Judith Herman (2015) as a stage of the trauma healing process that include 1) a healing relationship, 2) safety, 3) remembrance and mourning, 4) reconnection, and 5) commonality. Herman (2015) viewed reconnection to others and social causes as a type of attachment that promotes finding existential meaning in life.

Posttraumatic reconnection with the self includes thinking about the self and accepting situations that cannot be changed. Moreover, resilience connects cognitive, emotional, and behavioral elements to promote reconnection with the self, which provides solid ground for a traumatized individual to be reconnected with the community, overcome feelings of loneliness and thrive. This idea aligns with research that found that positive emotions are particularly significant for fostering resilience (Okvat \& Zautra, 2014). Posttraumatic reconnection focuses on the ability to continue living 
and remember the traumatic incident as a memory from which we learn lessons rather than trying to repress those memories and reject connections with emotions that lead to the development of severe mental health issues. 


\section{المجلة العربية للعلور التربوية والنفسية المجلد الخامس - العدد ( r ) أكتوبر ابr.r}

\section{References}

American Psychiatric Association. (2013). Diagnostic and statistical manual of mental disorders (5th ed.). https://doi.org/10.1176/appi.books.9780890425596

Bihlmaier, I., \& Schlarb, A. A. (n.d.). Self-efficacy and sleep problems. $\quad$ Somnologie, 20(4), 275-280. https://doi.org/10.1007/s11818-016-0085-1

Bonanno, G. A., Papa, A., \& O'Neill, K. (2001). Loss and human resilience. Applied \& Preventive Psychology, 10(3), 193206. https://doi.org/10.1016/S0962-1849(01)80014-7

Brooks, S. K., Webster, R. K., Smith, L. E., Woodland, L., Wessely, S., Greenberg, N., \& Rubin, G. J. (2020). The psychological impact of quarantine and how to reduce it: Rapid review of the evidence. Lancet, 912-921.

Carmassi, C., Gesi, C., Corsi, M., Cremone, I. M., Bertelloni, C. A., Massimetti, E., \& Dell'osso, I. (2018). Exploring PTSD in emergency operators of a major university hospital in Italy: A preliminary report on the role of gender, age, and education. Annals of General Psychiatry, 17(1), 17. https://doi.org/10.1186/s12991-018-0184-4.

Celinski, M., \& Allen, L. M. (2016). Universality of the challenge: Resilience-resourcefulness model. The Routledge International Handbook of Psychological Resilience, 59-74.

Creswell, J. W., \& Plano Clark, V. L. (2017). Designing and conducting mixed methods research (3rd ed.). SAGE Publications.

Connor KM,\& Davidson JR.(2003). Development of a new resilience scale: the Connor-Davidson Resilience Scale (CDRISC). Depress Anxiety.18(2):76-82. doi: 10.1002/da.10113. PMID: 12964174. 
Cormio, C., Muzzatti, B., \& Romito, F. (2017). . Post traumatic growth and cancer: A study 5 years after treatment end. Support Care Cancer, 25, 1087-1096.

De Guissme, L. \& Licata, L. (2017). Competition over collective victimhood recognition: When perceived lack of recognition for past victimization is associated with negative attitudes towards another victimized group. European Journal of Social Psychology 47(2):148-166

DOI:10.1002/ejsp.2244

Di Giuseppe, M., Miniati, M., Miccoli, M., Ciacchini, R., Grrù, G., Lo sterzo, R., Di silvestre, A., \& Conversano, C. (2020). Defensive responses to stressful life events associated with cancer diagnosis. Mediterranean Journal of Clinical Psychology, 8(1). https://doi.org/10.6092/2282-1619/mjcp2384

Eakman AM, Schelly C, Henry KL. Protective and Vulnerability Factors Contributing to Resilience in Post-9/11 Veterans With Service-Related Injuries in Postsecondary Education. Am J Occup Ther. 2016 Jan-Feb;70(1):7001260010p17001260010p10. doi: 10.5014/ajot.2016.016519. PMID: 26709427.

Gold, S. (2001). Not trauma alone. Brunner Routledge.

Herdiana, I., Handoyo, S., \& Suryanto, S. (2018). Family resilience: A conceptual review. Advances in Social Science, Education and Humanities Research. https://doi.org/10.2991/acpch17.2018.9

Hirschberger G. (2018). Collective Trauma and the Social Construction of Meaning. Frontiers in psychology, 9, 1441. https://doi.org/10.3389/fpsyg.2018.01441

Hooper, L. M. (2008). Defining and understanding parentification: Implications for all counselors. The Alabama Counseling Association Journal, 34, 34-43. 


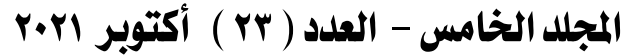

\section{المجلة العربية للعلوم التربوية والنفسية}

Lopez Castro, T., Saraiya, T., \& Hien, D. A. (2017). Women's mental health across the lifespan: Challenges, vulnerabilities, and strengths. Routledge.

Luthar, S., \& Brown, P. J. (2007). Maximizing resilience through diverse levels of inquiry: Prevailing paradigms, possibilities, and priorities for the future. Developmental and Psychopathology, 19, 931-955.

Marshall, C. and Rossman, G. (2016) Designing Qualitative Research. 6th Edition, SAGE, Thousand Oaks.

Mazur, L.B. \& Vollhardt, J.R. (2016). The prototypicality of genocide: implications for international intervention. Analyses of Social Issues and Public Policy, 16(1), 290--320. DOI: 10.1111/asap.12099

Miniati, M., Rucci, P., Benvenuti, A., Frank, E., Buttenfield, J., Giorgi, G., \& Cassano, G. B. (2009). Clinical characteristics and treatment outcome of depression in patients with and without a history of emotional and physical abuse. Journal of Psychiatry Research, 6(44), 302-309.

Mukhtar, S. (2020). Mental health and psychosocial aspects of coronavirus outbreak in Pakistan: Psychological intervention for public mental health crisis. Asian Journal of Psychiatry, 51. https://doi.org/10.1016/j.ajp.2020.102069

Okvat, H., \& Zautra, A. (2014). Sowing seeds of resilience: Community gardening in a post-disaster context. In K. G. Tidball \& M. E. Krasny (Authors), Greening in the red zone (pp. 73-90). Springer.

Pacella, M. I., Hruska, B., \& Delahanty, D. I. (2013). The physical health consequences of PTSD and PRSD symptoms: A metaanalytic review. Journal of Anxiety Disorders, 27(1), 33-46. https://doi.org/10.1016/j.janxdis.2012.08.004

Porges, S. W. (2011). The Norton series on interpersonal neurobiology. The polyvagal theory: Neurophysiological 
foundations of emotions, attachment, communication, and selfregulation. W W Norton \& Co.

Rana, W., Mukhtar, S., \& Mukhtar, S. (2020). Mental health of medical workers in Pakistan during the pandemic COVID-19 outbreak. Asian Journal of Psychiatry, 51. https://doi.org/10.1016/j.ajp.2020.102080

Rhodes, K. V., Lauderdale, D. S., Stocking, C. B., Howes, D. S., Roizen, M. F., \& Levinson, W. (2001). Better Health While You Wait: A Controlled Trial of a Computer-Based Intervention for Screening and Health Promotion in the Emergency Department. Retrieved from http://repository.upenn.edu/spp_papers/103

Robbins, A., Kaye, E., \& Catling, J. C. (2018). Predictors of student resilience in higher education. Psychology Teaching Review, 24(1).

Roditi, E., Bodas, M., Jaffe, E., Knobler, H. Y., \& Adini, B. (2019). Impact of stressful events on motivations, self- efficacy, and development of post-traumatic symptoms among youth volunteers in emergency medical services. International Journal of Environmental Research and Public Health, 16(9). https://doi.org/10.3390/ijerph16091613

Schäfer, I., Lotzin, A., Hiller, P., Sehner, S., Driessen, M., Hillemacher, T., Schäfer, M., Scherbaum, N., Schneider, \& Grundmann, J. (2019). A multisite randomized controlled trial of seeking safety vs. relapse prevention training for women with co-occurring posttraumatic stress disorder and substance use disorders. European Journal of Psychotraumatology, 10. https://doi.org/10.1080/20008198.2019.1577092

Schauer, M., \& Elbert, T. (2010). Dissociation following traumatic stress: Etiology and treatment. Zeitschrift für Psychologie/Journal of Psychology, 218(2), 109-127. https://doi.org/10.1027/0044-3409/a000018 


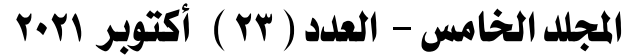

\section{المجلة العربية للعلوم التربوية والنفسية}

Smith, J. \& Osborn, M. (2007). Interpretative phenomenological analysis. Qualitative Psychology: A Practical Guide to Research Methods. 2nd Edition.

Soto, A. (2016). Alternative education and the development of resilience in youth who have abandoned school in Puerto Rico. Revista de Paz y Conflictos, 9(2), 223-243.

Trauma and recovery: The aftermath of violence from domestic abuse to political terror. (2015). ISBN-13:978-0465087303

The American Psychological Association, (2019). https://www.apa.org/about/division/digest/sharemembers/2019-highlights

Turliuc, M. N., Măirean, C., \& Dănilă, O. (2013). A multifaceted theory: Individual, family, and community resilience. A research review. In I. Rogobete \& A. Neagoe (Authors), Contemporary issues facing families: An interdisciplinary dialogue (pp. 33-53). Culture and Science Publishing.

U.S Department of Veterans Affairs. (2019). The National Center for PTSD.

https://www.ptsd.va.gov/understand/common/common_women asp

Vibha, Prabhu, A. N., Kamath, G. B., \& Venkatesh Pai, D. (2020). Keeping the country positive during the COVID19 pandemic: Evidence from India. Asian Journal of Psychiatry, 51, 102-118. https://doi.org/10.1016/j.ajp.2020.102118

Vinkers, C. H., Van Amelsvoort, T., Bisson, J. I., Branchi, I., Cryan, J. F., Domschke, K., Howes, O. D., \& Manchia, M. (2020). Stress resilience during the coronavirus pandemic. European Neuropsychopharmacology, 35, 12-16.

Wei, Y. I., Han, B., Liu, W., Liu, G., \& Huang, Y. (2004). Psychosomatic discomfort and related factors among 1,411 first-line SARS staff in Beijing. Traditional Chinese and Western Medicine, 6-12. 
Wu, P., Fang, Y., Guan, Z., Fan, B., Kong, J., Yao, Z., \& Hoven, C. W. (2009). The psychological impact of the SARS epidemic on hospital employees in China: Exposure, risk perception, and altruistic acceptance of risk. The Canadian Journal of Psychiatry, 54(5), 302-311. https://doi.org/10.1177/070674370905400504

Xiang, Y. T., Yang, Y., Li, W., Zhang, L., Zhang, Q., Cheung, T., \& Ng, C. H. (2020). Timely mental health care for the 2019 novel coronavirus outbreak is urgently needed. The lancet. Psychiatry, 7(3), 228-229. https://doi.org/10.1016/S22150366(20)30046-8 